\title{
The management of scarce water resources using GNSS, InSAR and in-situ micro gravity measurements as monitoring tools
}

\author{
Richard Wonnacott ${ }^{1}$, Chris Hartnady ${ }^{1}$, Jeanine Engelbrecht ${ }^{2}$ \\ ${ }^{1}$ Umvoto Africa (Pty) Ltd, Muizenberg, Cape Town, South Africa. \\ ${ }^{2}$ CSIR Meraka Institute, Stellenbosch, South Africa \\ Richard.w@umvoto.com
}

DOI: http://dx.doi.org/10.4314/sajg.v4i3.3

\begin{abstract}
South Africa is a water scarce country hence the careful monitoring and management of available water resources is critical for the wellbeing of the citizens of the country. A high percentage of the Earth's water supply is stored underground which can be extracted either through pumping or using artesian pressure. This paper describes the application of GNSS, InSAR and In-Situ Micro Gravity measurements for the monitoring of an artesian wellfield in the Oudtshoorn District in the Western Cape province of South Africa. GNSS receivers were run continuously for a period of 133 days between March and August 2014 to detect possible surface subsidence during pumping and artesian free flow extraction of water in the wellfield. Two InSAR scenes were processed, one during the peak period of water extraction from the wellfield and the other approximately 4 months after all boreholes were closed and pumps switched off. A micro-gravity campaign was conducted over two days in the wellfield with the gravity meter co-located at one borehole which was opened on the second day of the campaign. The results from the GNSS monitoring showed a subsidence of approximately 15 to $20 \mathrm{~mm}$ at the peak of the free flow and pump while those from the InSAR and microgravity measurements were largely inconclusive.
\end{abstract}

\section{Background}

South Africa is mostly a semi-arid, water-stressed country, with an average precipitation of about $450 \mathrm{~mm} / \mathrm{yr}$, well below the world average of about $860 \mathrm{~mm} / \mathrm{yr}$. Traditionally river water and surface water run-off has been stored in strategically placed large storage dams built in catchment areas. The supply of surface water either from rivers or runoff has been vulnerable to short and long term climate fluctuations with reduced water supplies being affected by drought (Hartnady et al., 2014). The desalination of sea water could be seen as an alternative source of water to supplement Municipal water supply but the process is expensive primarily because of the high cost of energy required to pump sea water or other saline water through membranes in a process known as reverse osmosis. Desalination plants using reverse osmosis have been installed in coastal towns such as Mossel Bay, Knysna and Plettenberg Bay (Mallory et al., 2012)

A high percentage of the Earth's fresh water is stored underground which can be extracted either through pumping or using artesian pressure through wells. In semi-arid areas such as the Klein Karoo in the Western Cape, aquifers may not recharge at a sufficiently sustainable rate relative to the rate of withdrawal, especially during periods of drought. In situations such as these, the extraction of water is therefore considered as "mining" of a non-renewable resource which has to be carefully managed (Hartnady et al., 2014).

\section{The Blossoms Well Field}

Considering the above and contemporary concern about global warming and its effects on water and food security, the Oudtshoorn Municipality in the Klein Karoo has embarked upon the exploration of a deep artesian aquifer situated approximately $30 \mathrm{~km}$ south of the town in the Northern foothills of the Outeniqua mountain range. In addition, the Municipality is developing what is known as the Blossoms Well Field of boreholes of between $500 \mathrm{~m}$ and $600 \mathrm{~m}$ deep within the area of the aquifer to supplement the current water supply for both the town and the surrounding rural areas. The aquifer is fed by water infiltrating primarily from the southern slopes of the Outeniqua range (see Figure 2). The area of the well field is shown in Figure 1 together with boreholes used in this project. A simplified profile AB of the geology extending from the Outeniqua range to the Blossoms wellfield in the vicinity of C1B3 and C1G1 is shown in Figure 2. 


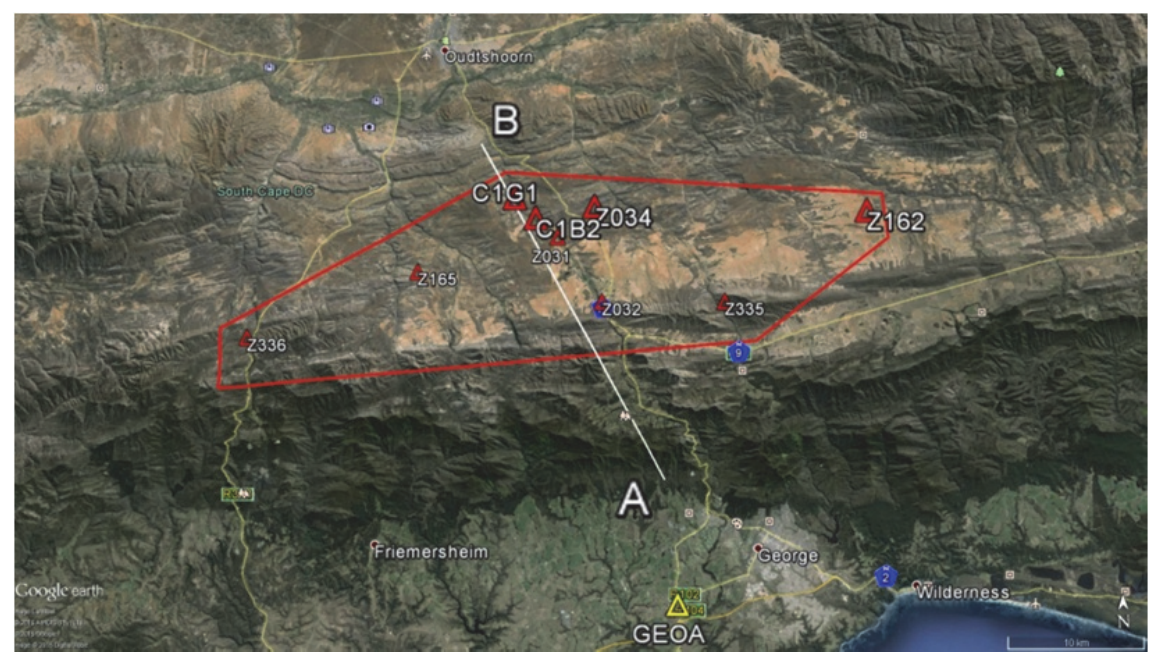

Figure 1. Blossoms wellfield and far-field boreholes (within the red polygon) relative to Oudtshoorn, George and the TrigNet station GEOA. Some boreholes are not shown for clarity. GNSS receivers were located at boreholes C1B2, C1G1, Z034 and Z162 for 133 days. C1B2 is approximately $25 \mathrm{~m} \mathrm{NW}$ of C1B3. The polygon is approximately $50 \mathrm{~km}$ by $11 \mathrm{~km}$ in extent. The line $\mathrm{AB}$ represents the geological profile in Figure 2.

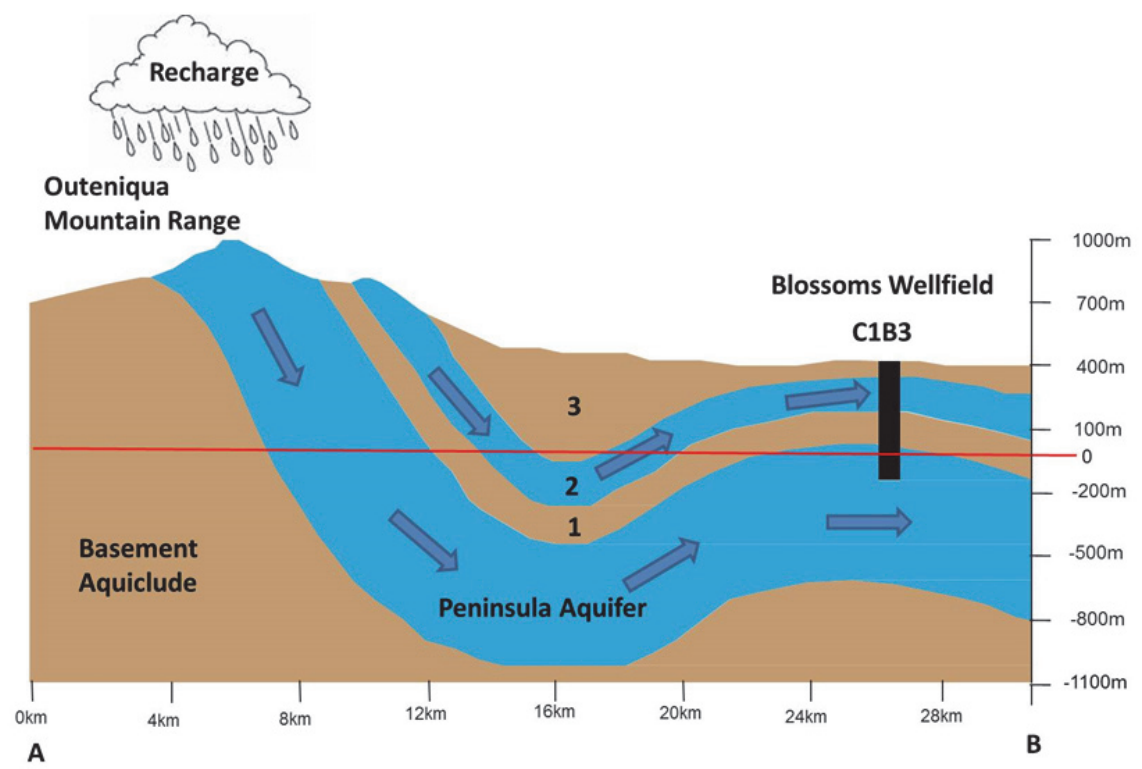

Figure 2. Simplified profile AB extending from the Outeniqua Mountain Range to the Blossoms Wellfield. Note that the well at C1B3 lies at $423 \mathrm{~m}$ above mean sea level and extends to approximately $170 \mathrm{~m}$ below mean sea level. $1=$ Winterhoek Mega-Aquitard; 2 = Skurweberg Aquifer; 3 = Gydo Mega-Aquitard. The horizontal and vertical scales are approximate.

Of major concern is the potential over-exploitation and the consequent "drying up" of the aquifer, hence the attention being paid to the management of the well field and its scarce water resource.

A key element in estimating the specific storage of deep confined aquifers is the skeletal-framework compressibility, but our knowledge of this quantity is uncertain and is based on simple rules and laboratory extrapolation. More sophisticated estimates can be obtained from pumping experiments in which the compaction and surface subsidence above the pumped aquifer is measured directly (Hartnady et al., 2014). Before the advent of Global Navigation Satellite Systems (GNSS), such measurements would have been done by periodically running precise levelling routes across the well field but such techniques are time consuming and only give an episodic indication of possible subsidence (or rebound). Continuously operating GNSS receivers placed on strategic points (boreholes) within the wellfield have the potential to give a continuous record of the state of the surface above pumped aquifers. At the same time, such GNSS measurements only give an indication at specific points whereas Interferometric Synthetic Aperture Radar (InSAR) has the potential to yield surface displacements at the sub-centimetre level at a ground resolution of $20 \mathrm{~m}$ over areas of approximately $100 \mathrm{~km}$ (Hartnady et al., 2014). InSAR, however, only gives a snapshot of the state of the surface at a specific time but, by using two or more scenes and using interferometric methods, changes in the surface (subsidence or rebound) can be estimated. 
A third technique that can be used to estimate surface subsidence or rebound is relative terrestrial and space-based gravimetry. Modern digital gravimeters have quoted accuracies of less than $5 \mu$ gal and, as a rule of thumb, $3.1 \mu$ gal is equivalent to approximately $0.01 \mathrm{~m}$ difference in height.

\section{Global Navigation Satellite Systems (GNSS)}

\subsection{GNSS Field Measurements}

The Oudtshoorn Municipality in conjunction with the Council for Geoscience, the Departments of Water and Sanitation and Science and Technology funded a project conducted by Umvoto Africa (Pty) Ltd to establish an infrastructure of monitoring plinths and pillars on boreholes within the Blossoms Wellfield, to be used primarily for GNSS monitoring of the surface during free flow and pump testing at a number of boreholes. $1.5 \mathrm{~m} \times 0.8 \mathrm{~m}$ concrete plinths were cast to a depth where solid rock was reached with reinforcing welded to the steel bore hole casing. Reinforced pillars, approximately $1.5 \mathrm{~m}$ high and $0.32 \mathrm{~m}$ in diameter were welded to the plinth reinforcing and cast onto the plinths. Stainless-steel adjustable antenna mounts were cast into the top of each pillar. An outer PVC jacket $0.4 \mathrm{~m}$ in diameter was also cast in place and the space between the outer jacket and the inner pillar was filled with thermal insulation to reduce distortion of the pillars during extreme temperatures ranges that can be experienced in the Oudsthoorn area (Figures 3 and 4).

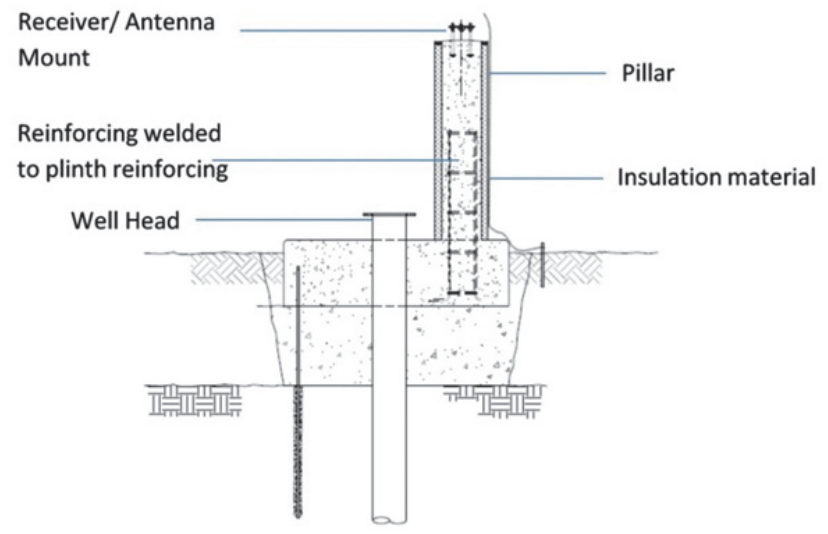

Figure 3. Typical construction of GNSS pillar on well head plinth (Diagram courtesy of RLH Consulting Engineers (Pty) Ltd.)

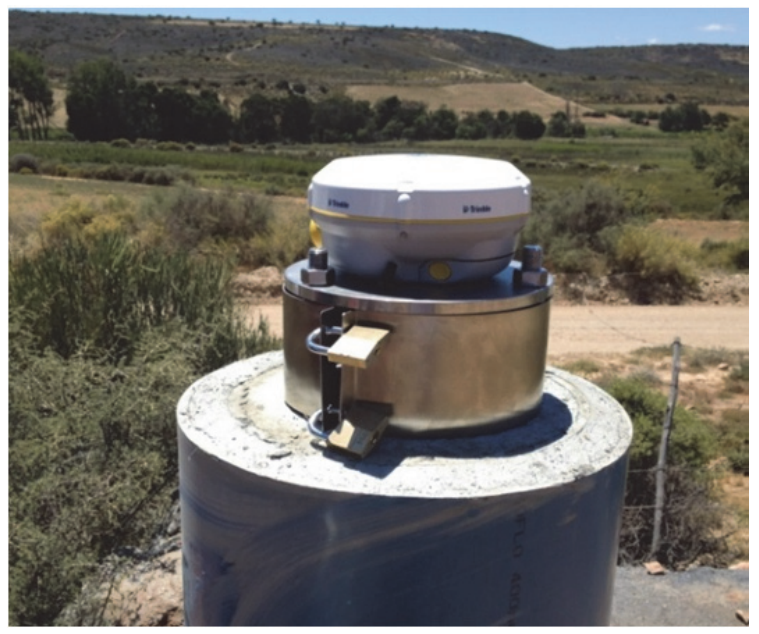

Figure 4. Receiver installed on stainless steel mount at Z031 with security band installed.

Four Trimble R4-3 receivers were purchased for the project. These are basic receivers with only a post-processing capability, no telecommunication options and $11 \mathrm{Mb}$ of available memory space. A solar panel connected to a $45 \mathrm{Ah}$ battery provided a power source for each of the receivers. Receivers were configured to record both GPS and GLONASS data at $30 \mathrm{sec}$ epochs down to a $3^{\circ}$ elevation mask. Once in operation, receivers had to be visited every three or four days to download daily data. The antenna is an integral part of the receiver and has an antenna type calibration published by the International GNSS Service (IGS). The receivers were run from 23 March until 2 August 2014 (133 days) during which time free-flow and pumping tests were done on selected boreholes between 12 May and 29 June 2014. 


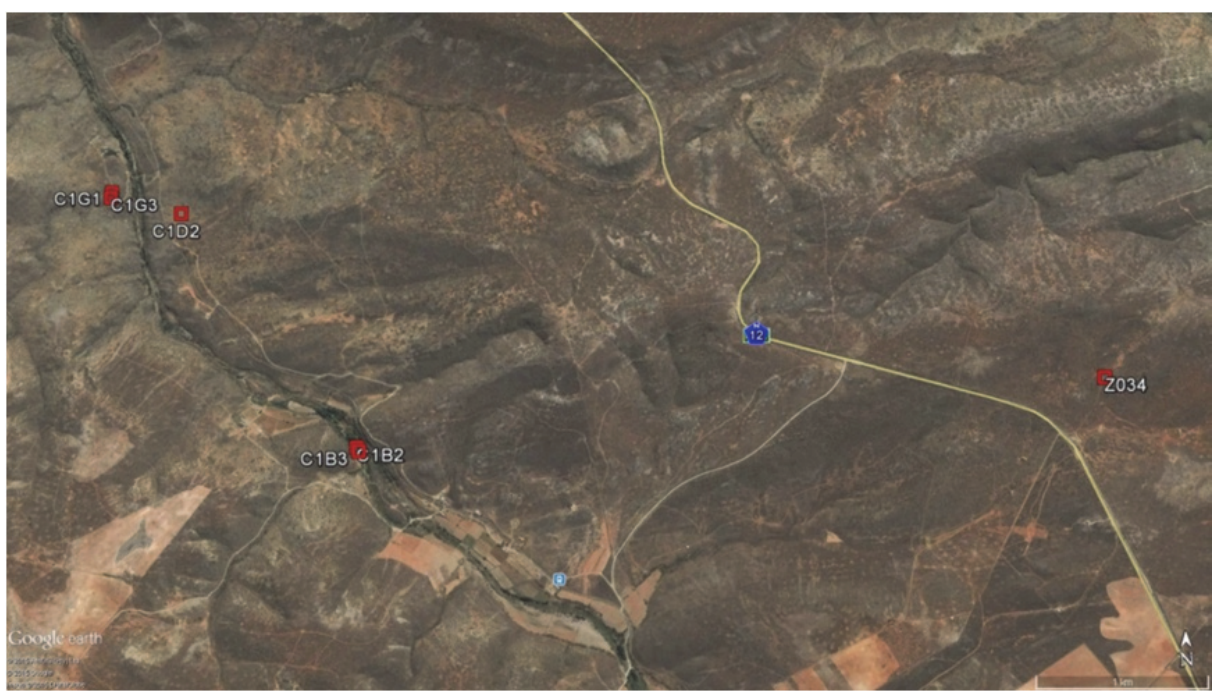

Figure 5. GNSS receivers placed on C1B2, C1G1, Z034 and Z162 (see Figure 1) from 23 March to 2 August 2014. Free flow or pump testing was conducted at C1B2, C1B3, C1D2, C1G1 and C1G3 between 12 May and 29 June 2014. Z162 not shown.

\subsection{GNSS Processing}

Processing the daily RINEX files was done using the Bernese GNSS Software v5.2 (BSW 5.2). The final processing of BSW 5.2 is a three-stage process in which tropospheric corrections are estimated first, followed by the resolution of ambiguities and finally the estimation of co-ordinates and the creation of a set of normal equations. Both L1 and L2 frequencies were used in the first two stages. Because the network was reasonably small $(27 \mathrm{~km} \times 3 \mathrm{~km})$ and the highest possible precision was required, only L1 was used together with daily global ionosphere models for the final stage, to reduce ionosphere-induced scale biases (Dach et al., 2007). The IGS daily final orbits and weekly Earth rotation parameters were used in processing together with ocean-loading corrections. Although both GPS and GLONASS data was logged, only GPS was used in the processing to avoid any biases that may exist between the two systems. All logged data above a $3^{\circ}$ elevation mask was used to estimate tropospheric corrections and to resolve ambiguities. As the purpose of the processing was essentially to estimate changes in height, only data above $10^{\circ}$ was used in the final processing to reduce the effect of atmospheric refraction at low elevations. Only data from the four receivers in the wellfield area, and no IGS or TrigNet stations, were used in the processing to avoid any atmospheric effects from distant points that may influence the processing. The network was processed, therefore, as local network with no connection to the ITRF or Hartebeesthoek 94, as the primary purpose of the project was to estimate changes in height on the boreholes (subsidence or rebound) resulting from free-flow or test pumping. The borehole at Z162 is a monitoring borehole $27 \mathrm{~km}$ from the wellfield, was considered to be far enough away not to be influenced by any aquifer testing, and was heavily constrained in the processing. All position changes therefore became relative to Z162.

\subsection{GNSS Results}

A comparison of the 133 daily solutions gave an rms of unit weight (wrms) of approximately $3 \mathrm{~mm}$ for the Northing and Easting components and $6 \mathrm{~mm}$ for the Up component at C1B2, C1G1 and Z034, while the wrms for all three components at Z162 was less than $0.5 \mathrm{~mm}$. 


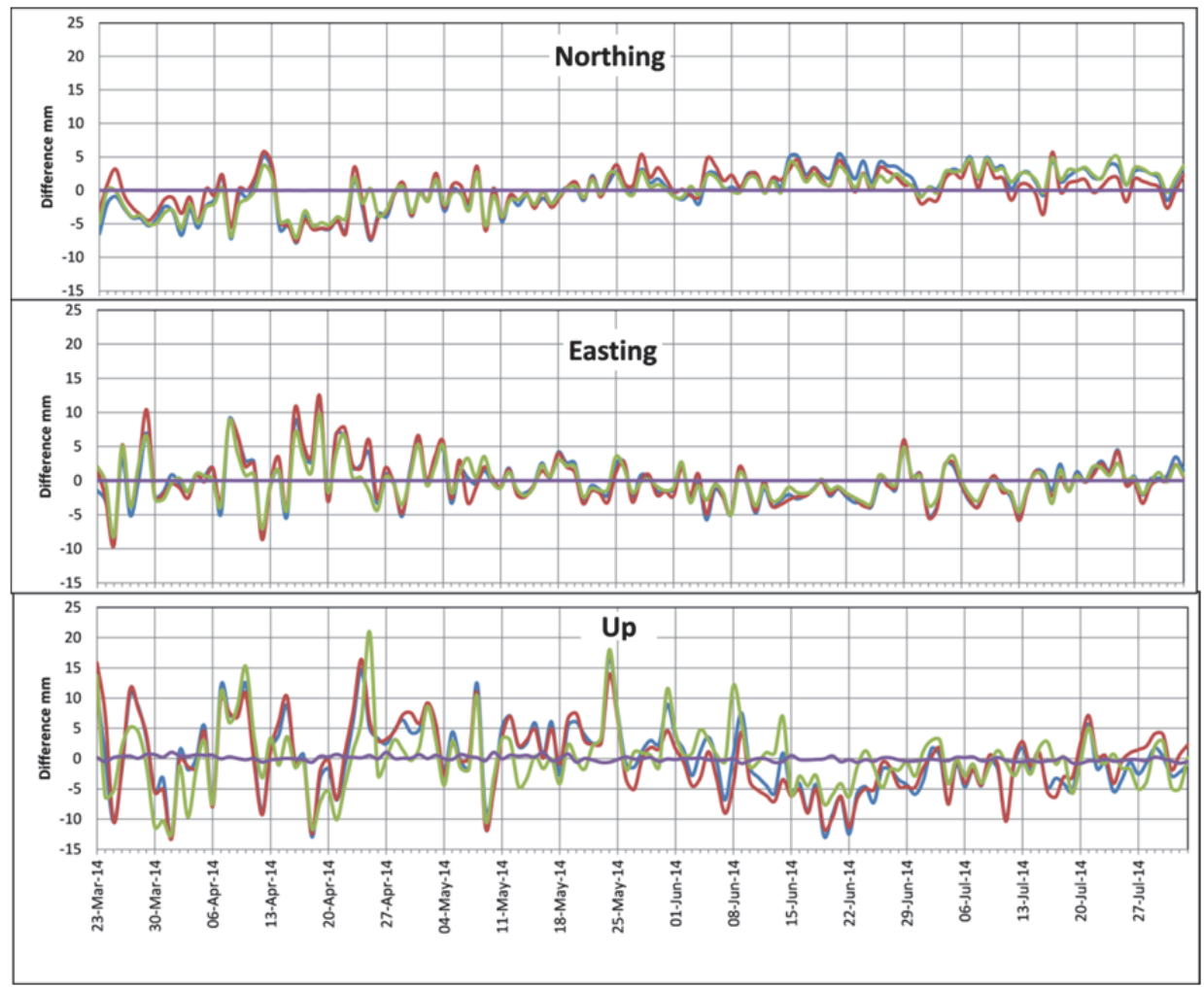

Figure 6. Plots of daily differences in Northing, Easting and Up at C1B2 (blue), C1G1 (red), Z034 (green) and Z162 (purple). Free-flow and pump testing was conducted between 12 May and 29 June. All measurements refer to mid-day.

Large variations in the differences in all three components occur during the period 23 March to approximately 11 May. This corresponds roughly to a period around the equinox when it is known that solar activity is at its highest and thus having the highest influence on the ionosphere (Yizengaw and Essex, 2000; Liu et al., 2010; Habarulema, 2010). From 11 May until the receivers were shut off on 2 August, i.e, during winter months, the variations in the differences are not as large.

In the period during which free-flow only tests were conducted, the differences in height show a slow subsidence from 12 May until approximately 9 June. The subsidence shows a marked increase from 9 June and 18 June when pumping started at C1B3 and C1G3, respectively. On the 23 June difficulties were experienced with the pump at C1B3 when the results show the commencement of a rebound. The remaining pump at C1G1 was shut off on 25 June and all boreholes were closed on 29 June (see Figure 7).

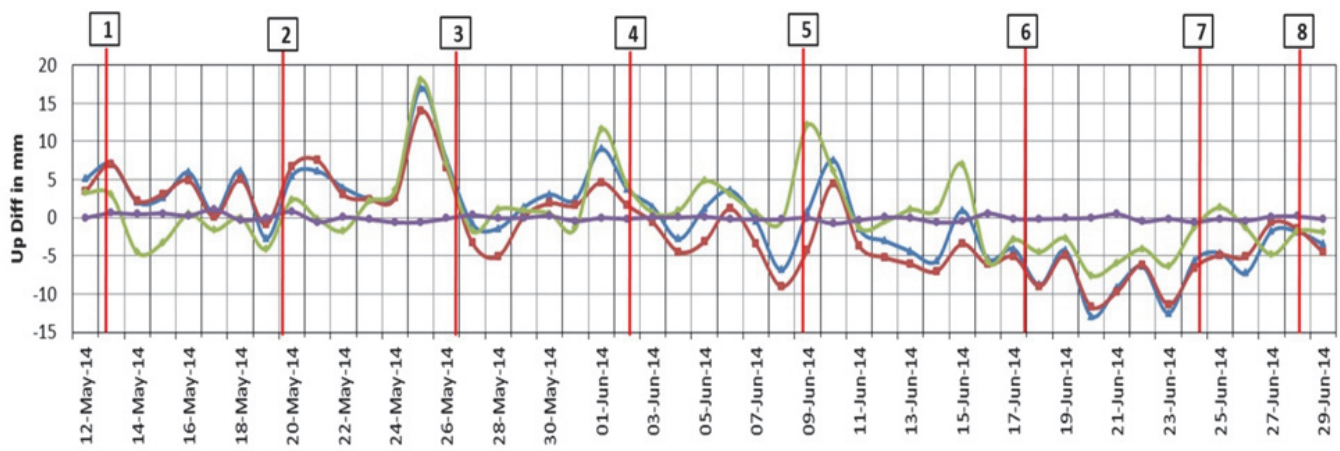

Figure 7. Plot of subsidence in mm at C1B2 (blue), C1G1 (red), Z034 (green) and Z162 (purple). $1=\mathrm{C} 1 \mathrm{G} 3$ free-flow start, $2=\mathrm{C} 1 \mathrm{D} 2$ free-flow start, $3=\mathrm{C} 1 \mathrm{G} 1$ free-flow start, $4=\mathrm{C} 1 \mathrm{~B} 3$ free-flow start, $5=\mathrm{C} 1 \mathrm{~B} 3$ test-pumping start, $6=\mathrm{C} 1 \mathrm{G} 3$ test-pumping start, $7=$ pumping stopped, $8=$ Shut-in of all wells

The changes in the Up components at C1B2 and C1G1 in Figure 7 are almost identical and are on boreholes where free-flow and test pumping took place either at these boreholes themselves or at boreholes within $50 \mathrm{~m}$ of the each of the two boreholes. The changes in the Up component at Z034 are similar to those at C1B2 and C1G1 but a lot smaller. It should be noted that Z034 is approximately $4 \mathrm{~km}$ to the East of the boreholes C1B2 and C1G1 and the question arises whether or not Z034 is also affected by the aquifer testing or is it an artefact of the GNSS processing. The subsidence 
shown in C1B2 and C1G1 is approximately $15 \mathrm{~mm}$ while that at Z034 is less than $10 \mathrm{~mm}$. The location of each borehole is shown in Figures 1 and 5.

The rate of water flow from the boreholes during free flow and pump testing was measured and converted to an accumulated total volume extracted per day (Ml/day). The total volume extracted was compared with the amount of subsidence measured with the GNSS receivers at C1B2, C1G1 and Z034. It must be pointed out that the total volume extracted includes both free flow and pumped extraction. Figure 8 shows the relationship between the total accumulated volumes of water extracted against the amount of subsidence as measured at C1B2 only. The negative correlation between the subsidence and the total accumulated volume of water extracted is as expected i.e. the greater the volume of water extracted the great the amount of subsidence.

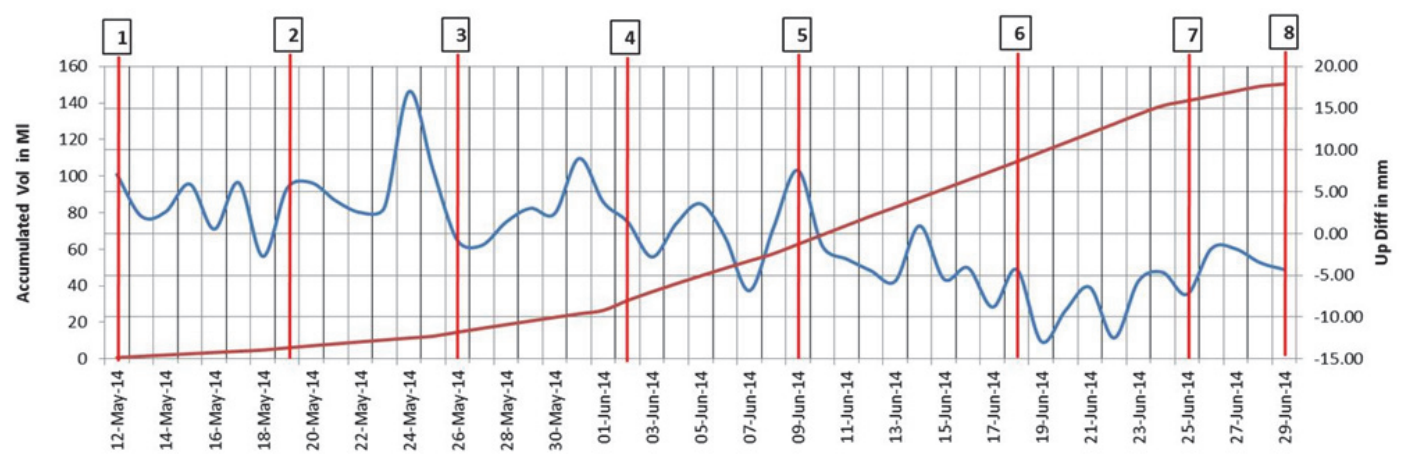

Figure 8. Plot of subsidence in mm at C1B2 (blue curve) versus total accumulated water extracted from the wellfield in megalitres (Ml) (red curve). See Figure 7 for designation of event markers.

The Pearson correlation coefficient ( $r$ ) for the subsidence against volume water extracted is -0.711 and -0.690 for boreholes C1B2 and C1G1, respectively is shown in Figure 9.

The moderate magnitude of the correlation coefficient at these two boreholes is probably influenced by a number of external factors such as the recharge rate in the aquifer which is not being measured directly. The subsidence will be influenced by a net loss of water and not by the extraction rate only.

The correlation coefficient at Z034 shows less of a correlation which is, once again, an intuitively expected result. This is consistent with the small subsidence measured and the distance of this borehole from the main well field where pumping and extraction took place (Figure 9). The Pearson correlation coefficient (r) for Z034 is -0.366.

In all cases, the error in measuring flow rates and in the GNSS measurements will contribute to the moderate to low correlation coefficients.

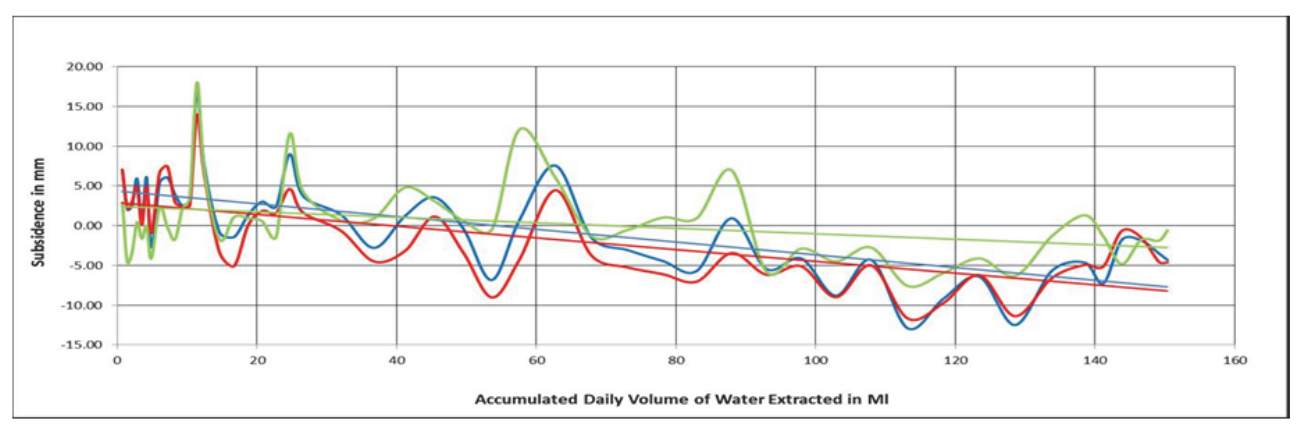

Figure 9. Correlation between subsidence at C1B2 (blue), C1G1 (red) and Z034 (green) against accumulated volume of water extracted from the well field in Mega litres (Ml). Linear trends give Pearson correlation co-efficients (r) of -0.711, -0.690 and -0.366 at C1B2, C1G1 and Z034 respectively.

Neither the correlation coefficients nor a comparison between total volume extracted with motions in the $\mathrm{N}$ and $\mathrm{E}$ components at all three boreholes has been given as the movements are very small (3-4 mm) and close to the approximately $3 \mathrm{~mm}$ wrms of the GNSS daily differences (Hartnady et al, 2014).

\subsection{Potentiometric Surface Level Monitoring}

Before, during and after the free flow and pump testing in the Blossoms wellfield, the aquifer pressure which can be converted to the potentiometric surface level (PSL) was tested on a continuous basis. The PSL measured at C1B2, which is approximately $25 \mathrm{~m} \mathrm{NNW}$ of the main production well C1B3, can be correlated with the U displacement 
measured at C1B2 (see Figure 10). A fall in the PSL from approximately $485 \mathrm{~m}$ to $420 \mathrm{~m}$ is associated with a $12-16$ $\mathrm{mm}$ drop in the elevation (subsidence) of the C1B2 GNSS receiver (see Figure 10). When the co-variation of PSL and $\mathrm{U}$ displacement is plotted as a stress (PSL)-versus-strain (U) diagram (Figure 11), the linear slope of the relation (U in $\mathrm{mm} / \mathrm{PSL}$ in $\mathrm{m}$ ) is a measure of the elastic-storage co-efficient of the aquifer, $\mathrm{S}_{\mathrm{ke}}$. The GNSS-derived $\mathrm{S}_{\mathrm{ke}}$ value thus obtained $\left(\sim 1.82-2.10 \times 10^{-4}\right)$ is within the range expected from a deep, fractured-rock system like the Peninsula Aquifer and is close to values obtained by analysis of previous test-pumping data (Hartnady et al., 2014).

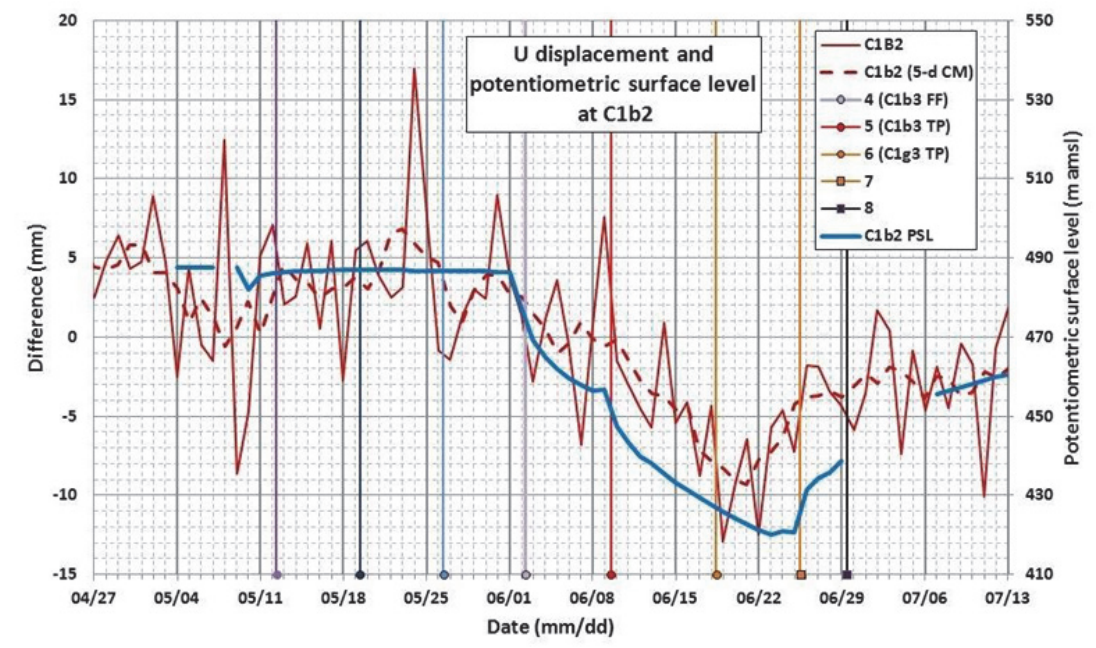

Figure 10. Temporal plot of vertical displacement and potentiometric surface level for C1B2. The event markers to be the same as Figures 7 and 8 .

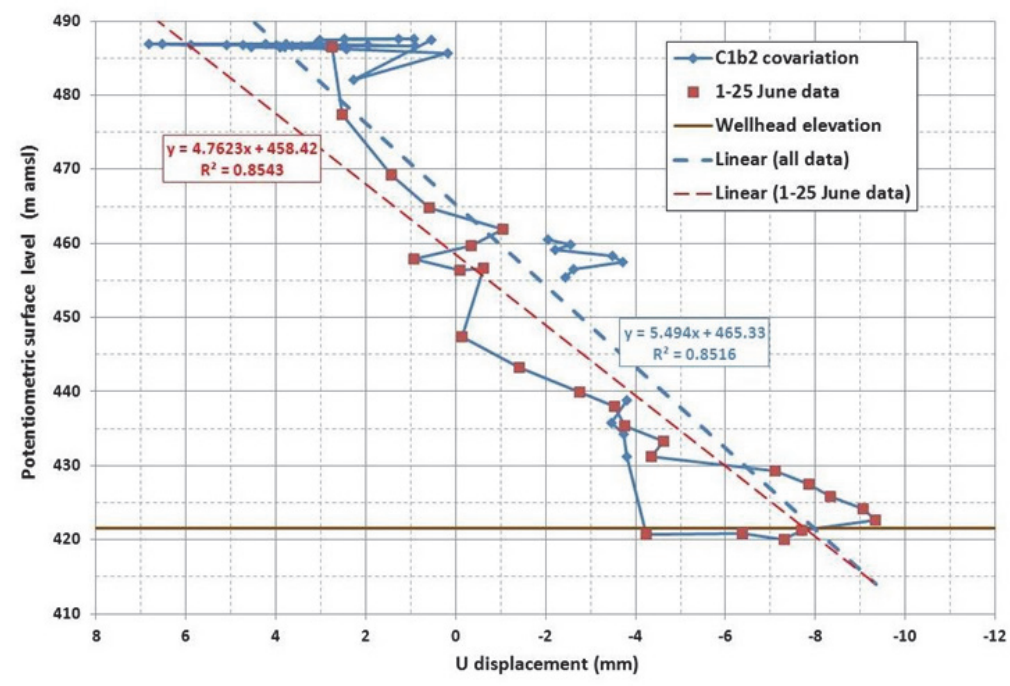

Figure 11. Stress-strain relationship for C1B2 with wellhead elevation shown at $421.61 \mathrm{~m}$ above mean sea level

\section{Differential Interferometric Synthetic Aperture Radar (dInSAR)}

\section{1 dInSAR Data}

By comparing two Synthetic Aperture Radar (SAR) satellite images acquired at different dates it is possible to detect small changes in the Earth's surface using interferometric methods. This technique is known as Interferometric SAR, or InSAR, has been widely used for the detection of $\mathrm{cm}$ to $\mathrm{mm}$ scale deformation, including deformation due to groundwater abstraction (Chaussard et al., 2014; Erban et al., 2014; Bawden et al., 2001; Amelung et al. 1999; Aobpaet et al., 2013). Comparison of deformation rates by InSAR techniques generally compare well with deformation rates obtained by traditional surveying techniques including levelling (Aobpaet et al., 2013; Amelung et al. 1999) and GPS surveys (Abidin et al., 2009). In general, measurements of surface deformation can have a precision of $2-5 \%$ of the SAR wavelength which typically ranges from $3 \mathrm{~cm}$ to $30 \mathrm{~cm}$ which implies millimetre to centimetre precision in surface displacement between two satellite passes. 
To gauge the suitability of InSAR for the monitoring of ground deformation as a result of water extraction in the Blossoms wellfield, SAR data was acquired to coincide as closely as possible to the dates during which the aquifer tests were conducted between May and June 2014. Two Single Look Complex (SLC) scenes from the Canadian RADARSAT-2 satellite were acquired each covering an area of approximately $90 \mathrm{~km} \times 50 \mathrm{~km}$ with a ground resolution of approximately $5 \mathrm{~m}$. The two scenes were captured on 22 June and 26 October 2014 respectively and covered the same area (See Figure 12). It should be pointed out that the scene captured on 22 June was six days before all free flow and pump testing in the wellfield ceased while, apart from a short ( 5 hour) free flow test at C1B3 on 2 October, no prolonged testing took place between 29 June and 26 October 2014 (Hartnady et al, 2014).

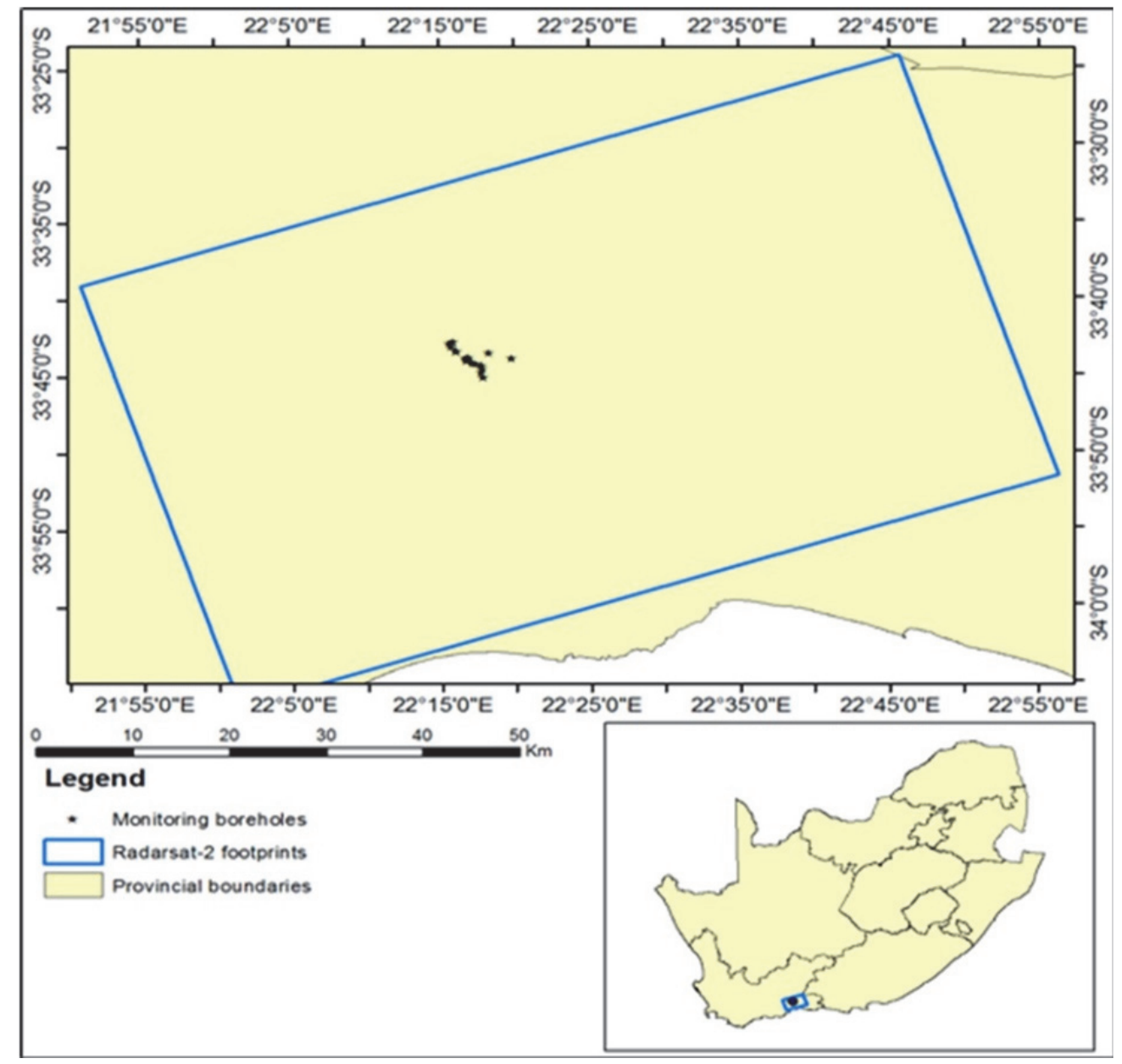

Figure 12. RADARSAT-2 footprints (blue boundary) and positions of the monitoring boreholes in the area of interest.

\section{2 dInSAR Processing}

The extraction of deformation measurements from the SLC SAR scenes through a traditional interferometric processing sequence involves several processing steps including the removal of topographic and orbital phase from the interferogram by a process known as interferogram flattening which uses known topographic phase derived from an external digital elevation model as input. The result of the processing is known as a differential interferogram and is, in theory, a dataset in which topographic and orbital phase contributions are removed. Any residual phase contributions are only due to surface deformation and potentially atmospheric artefacts. The interferogram essentially provides an indicator of interferometric phase produced by any surface deformation as well as a change in phase due to delays of the signal by atmospheric conditions at the time of image acquisition. Although the interferogram alone does not provide actual deformation measurements (only phase measurements between - and + are provided), the interferogram is useful for the visual assessment of deformation related fringes since it usually manifests as concentric fingerprint-like fringe patterns (similar to the pattern in Figure 13). 


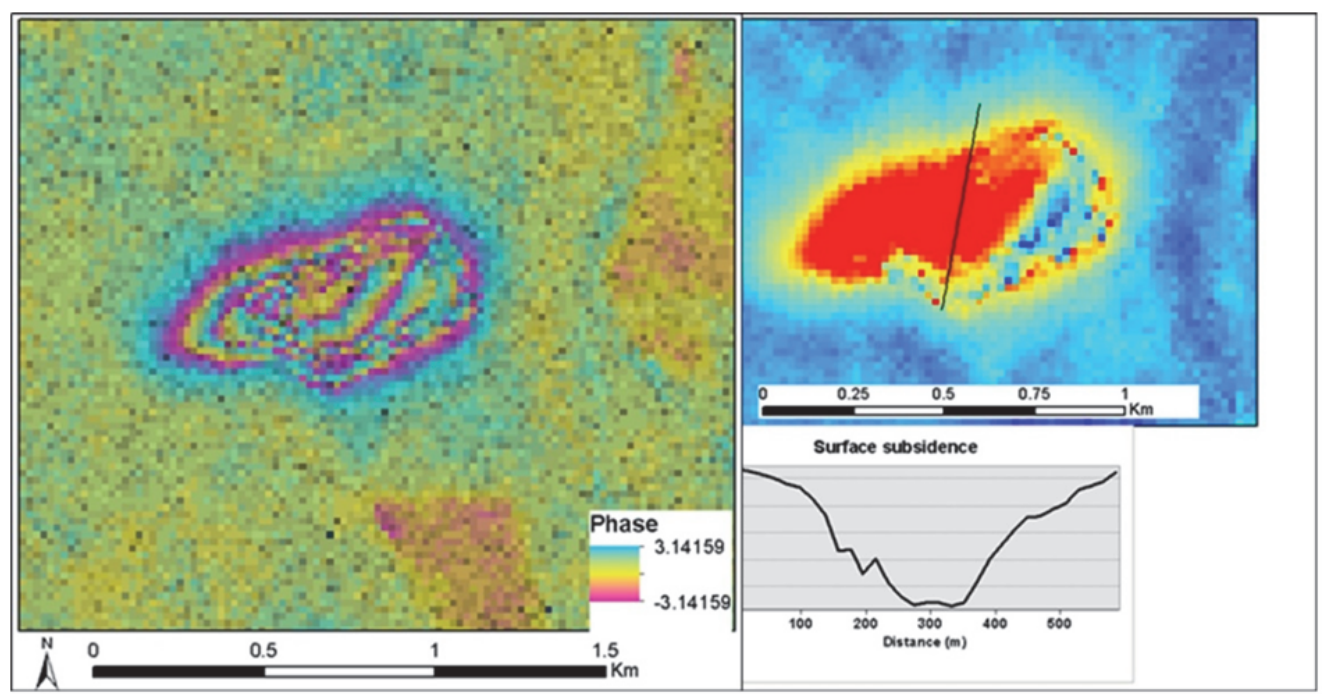

Figure 13. An example of a filtered differential interferogram in an area undergoing surface subsidence (left) and the derived deformation map with subsidence profile.

\section{3 dInSAR Results}

The differential interferogram generated for the Blossoms wellfield and surrounds is shown in Figure 14. Although characteristic deformation related fringes could not be identified, the deformation map, generated from the differential interferogram, reveals negative deformation features associated with borehole C1B2, where ground-based monitoring revealed systematic surface subsidence associated with water abstraction (see Figure 7). However, the results are considered to be inconclusive since atmospheric effects may be affecting the interferometric measurement in an unpredictable way. Furthermore, the presence of riparian vegetation in the vicinity of the well field introduced unacceptable levels of noise which limits the extraction of high confidence deformation measurements. The inconclusive result is due to the lack of InSAR data (only two scenes were available for the observation period). It is recommended that future investigations focus on the use of a large stack of SAR scenes over the observation period and advanced signal processing techniques, including the persistent scatterer (PS) and Small-Baseline subset techniques (SBAS). This will enable the retrieval of deformation rates in the order of millimetres per annum while minimising the influence of fluctuating atmorpheric conditions over time.

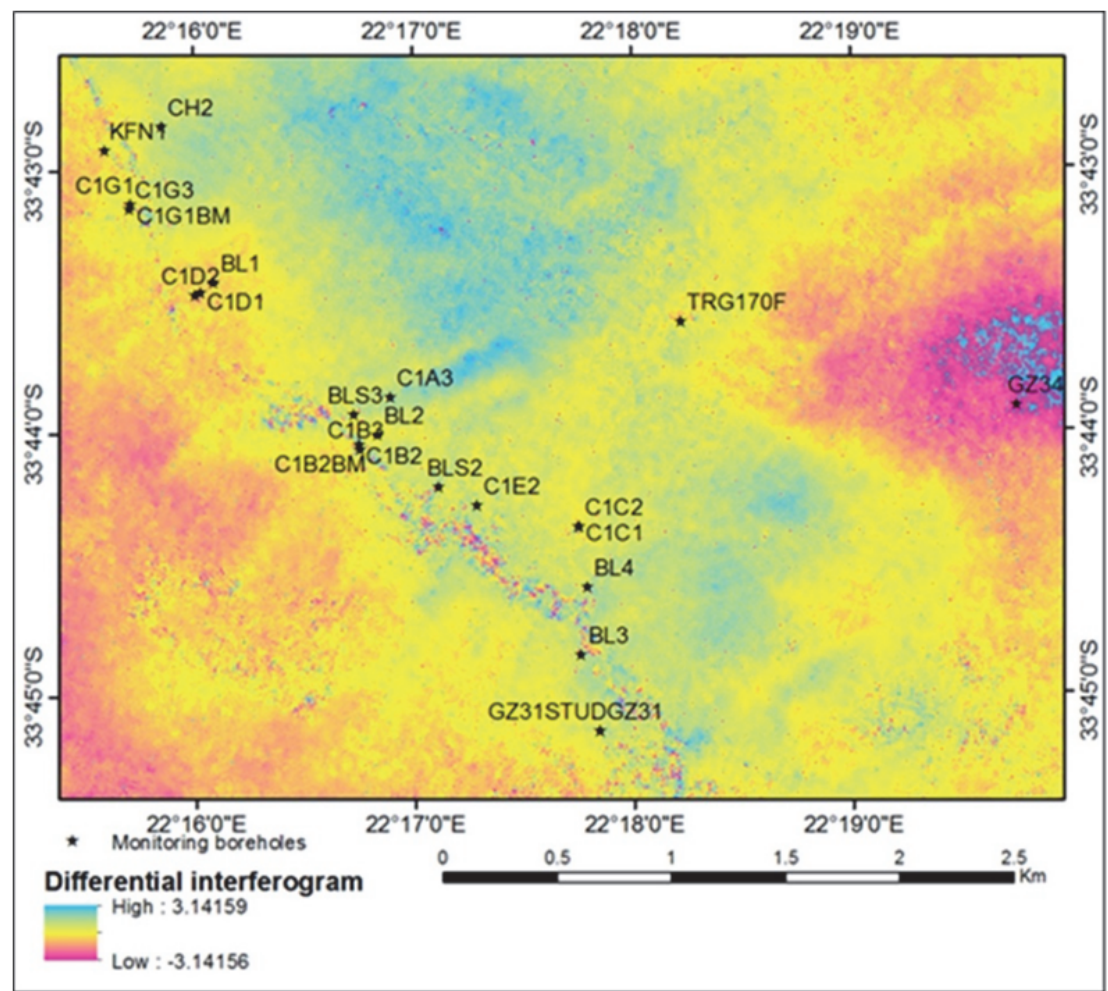

Figure 14. The differential interferogram in the vicinity of the monitoring boreholes. 


\section{In-situ Micro-gravity Measurements}

Besides the testing of GNSS and dInSAR to monitor and detect ground deformation as a result of free low and pump testing in the wellfield, a short (5 hour) test was conducted on 2 October using a Scintrex Micro-gravity meter at C1B2. Measurements were recorded from approximately $10 \mathrm{~h} 00$ until $18 \mathrm{~h} 30$. The well at C1B3, approximately $28 \mathrm{~m}$ SE of C1B2 was opened in a free flow test from $12 \mathrm{~h} 30$ to $17 \mathrm{~h} 30$. GNSS receivers were set up at C1B2, C1G1, Z034 and Z031 and allowed to run until approximately $12 \mathrm{~h} 00$ on 3 October.

The results of this test, however, were inconclusive because of the very short duration that the well at C1B3 was opened. Unfortunately, for various logistic reasons, it was not possible to run the gravity meter for a longer duration.

Although the above test was not very successful, gravity measurements have been shown to provide a useful tool for the measurement and monitoring of ground subsidence resulting from numerous natural and anthropogenic causes including the abstraction of groundwater and gas. Zerbini et al (2007) processed and combined data from a Superconducting Gravimeter, four GNSS base stations, InSAR and VLBI to give a mean rate of subsidence of -3.33 $\pm 0.09 \mathrm{~mm} / \mathrm{yr}$ in the South Eastern Po Plain in Italy. It must be pointed out that these results were obtained using data over an 8 year period from 1996 to 2004 .

Microgravity meters were also used with success for the monitoring of groundwater storage changes in an unconfined aquifer in Madison in the USA (Koth and Long, 2012). Once again it must be pointed out the data span for this monitoring was over a 3 year period from 2009 to 2012. Similar results have been obtained elsewhere, but in all cases the observation period was much longer than that attempted in this project.

\section{Conclusions}

The use of all three techniques as described in this paper have the potential to be used monitoring tools for the management of water extraction from an artesian wellfield such as that at Blossoms in the Oudtshoorn district. These technologies, GNSS, dInSAR and in-situ gravity measurements, are non-invasive and, besides the construction of stable platforms on which to place the GNSS receivers and gravity meter, do not require the costly drilling of monitoring boreholes and the installation of expensive related monitoring equipment. Of the three technologies tested, the GNSS has shown a great deal of promise which is able to monitor surface subsidence and rebound on a daily basis. The results of the GNSS monitoring in this project showed an approximately 15 to $20 \mathrm{~mm}$ subsidence at the peak of the free flow and pump testing. Once all boreholes were shut and pumps switched off, the GNSS monitoring also showed a rebound to the normal surface before the commencement of the testing. The drop in the potentiometric level surface correlated well with the GNSS detected subsidence detected at C1B2.

It is suggested that where local authorities rely on ground water to supplement municipal water supply especially in times of drought, serious consideration should be given to the installation of an array of permanent continuously operating GNNS receivers to assist with the monitoring and management of water abstraction from well fields. Data from such a network of permanent GNSS stations could also be used for a variety of other applications in Municipal areas such as serving as base stations for engineering, topographical and cadastral surveys. Further experimentation on the use of in-situ micro-gravity measurements and dInSAR should be carried out before these techniques can be used on a regular basis to provide independent measurements of subsidence or rebound. In all cases special care and consideration must be taken with the construction of instrument monumentation, measurement and data processing.

\section{Acknowledgements}

This research was funded by the Department of Science and Technology for the South African Council for Geoscience programme on the creation of a South African Geological Hazards Observation System.

The authors also acknowledge the contributions made by:

- The Municipality of Oudtshoorn for access to monitoring borehole data in the blossoms wellfield area and construction of boreholes, borehole plinths and pillars;

- $\quad$ The Department of Water and Sanitation for access to monitoring borehole data in the far field areas;

- $\quad$ Staff of Umvoto Africa (Pty) Ltd for field operations; and

- The three anonymous reviewers for their positive and constructive input to the paper. 


\section{References}

Abidin, H., Andreas, H., Gumilar, I., Wangsaatmaja, S., Fukuda, Y., Deguchi, T., 2009. Land subsidence and groundwater extraction in Bandung Basin, Indonesia. IAHS Publ. 329: 145-156.

Amelung, F., Galloway, D.L., Bell, J.W., Zebker, H.A., Laczniak, R.J., 1999. Sensing the ups and lowns of Las Vegas: InSAR reveals structural control of land subsidence and aquifer system deformation. Geology., 6: 483-486.

Aobpaet, A., Cuenca, M.C., Hooper, A., Trisirisatayawong, I., 2013. InSAR time-series analysis of land subsidence in Bangkok, Thailand. International Journal of Remote Sensing., 34 (8): 2969-2982.

Bawden, G.W., Thatcher, W., Stein, R.S., Hudnut, K.W., Peltzer, G., 2001. Tectonic contraction across Los Angeles after removal of groundwater pumping effects. Nature., 412: 812-815.

Chaussard, E., Wdowinski, S., Cabral-Cano, E., Amelung, F., 2014. Land subsidence in central Mexiso detected by ALOS InSAR time-series. Remote Sensing of Environment., 140: 94-106.

Dach, R., Hugentobler, U., Fridez, P., Meindl, M. (eds), 2007. Bernese GPS Software Version 5.0. Astronomical Institute, University of Berne.

Erban, L.E., Gorelick, S.M., Zebker, H.A., 2014. Groundwater extraction, land subsidence, and sea-level rise in the Mekong Delta, Vietnam. Environ. Res. Lett., 9: doi:10.1088/1748-9326/9/8/084010.

Habarulema, J.B., 2010. A Contribution to TEC modelling over Southern Africa using GPS data., PhD Thesis, Rhodes University.

Hartnady, C.J.H., Wonnacott, R., Engelbrecht, J., Stettler, R., 2014. Space-geodetic (Earth) Observation in Support of Hydroseismic and Hydro-meteorological Hazard Mapping, Drought Mitigation and Groundwater Resource Assessment. Contribution to unpublished report of Council for Geoscience to Department of Science and Technology South African Geological Hazards System.

Koth, K.R., Long, A.J., 2012. Microgravity methods for characterization of groundwater-storage changes and aquifer properties in the karstic Madison aquifer in the Black Hills of South Dakota, 2009-12: U.S. Geological Survey Scientific Investigations Report 2012-5158, 22 p.

Liu, L., He, M., Yue, X., Ning, B., Wan, W., 2010. Ionosphere around equinoxes during low solar activity. J Geophysical Res. 115, A09307, doi: 10.1029/2010JAA015318.

Mallory, S. J. L., Ballim, F., Pashkin, J., Ntuli, C., (2012). Introducing Desalination Plants into System Operation Rules for Bulk Water Supply Systems. http://www.ru.ac.za/static/institutes/iwr/SANCIAHS/2012/documents/033 Mallory.pdf

Viewed 16 Dec 2014.

Yizengaw, E., Essex, E. A., (2000). Storm Time Seasonal Variation of TEC in the Southern Hemishpere Mid-Latitude Regions Using Signals from GPS Satellites. http://www.igpp.ucla.edu/public/ekassie/Publications/Yizengaw_OIST4.pdf Viewed 22 Aug 2014.

Zerbini, S., B. Richter, F. Rocca, T. van Dam, and F. Matonti (2007). A Combination of Space and Terrestrial Geodetic Techniques to Monitor Land Subsidence: Case Study, the South Eastern Po Plain, Italy, J. Geophys. Res., 112, B05401, doi:10.1029/2006JB004338. 